\title{
Direct control of active and reactive power for a grid-connected single-phase photovoltaic inverter
}

\author{
Eyad Radwan', Mutasim Nour², Ali Baniyounes ${ }^{3}$, Khalid S. Al-Olimat ${ }^{4}$, Emad Awada ${ }^{5}$ \\ ${ }^{1,3}$ Department of Electrical Engineering, Applied Science Private University, Amman, Jordan \\ ${ }^{2}$ School of Engineering \& Physical Sciences, Heriot-Watt University, Dubai, United Arab Emirats \\ ${ }^{4}$ Department of Electrical \& Computer Engineering and Computer Science, Ohio Northern University, Ohio, United \\ States of America \\ ${ }^{5}$ Department of Electrical Engineering, Philadelphia University, Amman, Jordan
}

\section{Article Info}

Article history:

Received Sep 21, 2020

Revised Jan 19, 2021

Accepted Jan 31, 2021

\section{Keywords:}

Distributed generation

Grid-connected

Maximum power tracking

Photovoltaic array

Reactive power

Renewable energy

Single-phase inverter

\begin{abstract}
This paper presents a single-phase grid-connected photovoltaic system with direct control of active and reactive power through a power management system of a Photovoltaic inverter. The proposed control algorithm is designed to allow maximum utilization of the inverter's available KVA capacity while maintaining grid power factor and current total harmonic distortion (THD) requirements within the grid standards. To reduce the complexity and improve the efficiency of the system, two independent PI controllers are implemented to control single-phase unipolar PWM voltage source inverter. One controller is used to control the power angle, and hence the active power flow, while the other controller is used to control the reactive power, and consequently the power factor by adjusting the voltage modulation index of the inverter. The proposed system is modelled and simulated using MATLAB/Simulink. The PV inverter has been examined while being simultaneously connected to grid and local load. Results obtained showed the ability of the PV inverter to manage the active and reactive power flow at, and below rated levels of solar irradiances; resulting in an increased inverter utilization factor, and enhanced power quality. The proposed system, was capable of operating at power factors in the range of 0.9 lead or lag for reactive power compensation purposes and delivered its power at a wide range of solar irradiance variations.
\end{abstract}

This is an open access article under the CC BY-SA license.

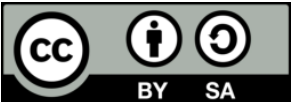

\section{Corresponding Author:}

Eyad Radwan

Department of Electrical Engineering

Applied Science Private University

Al Arab street, Amman, Jordan

Email: e_redwan@asu.edu.jo

\section{INTRODUCTION}

Distributed generation (DG) systems that depend on renewable energy sources have been gaining an increased interest as alternative sources of energy to power small residential and medium commercial installations. The operation of DG systems to supply power to local loads and in grid-connected manner provides a number of advantages, such as: the possibility of generating power closer to consumers leads to reduced power losses, increased voltage levels, improved reliability, and others [1], [2]. Therefore, the integration of DG systems (wind, solar) in distribution networks has increased rapidly and has attracted significant attention in recent years. Among the various DG systems, photovoltaic (PV) energy is one of the most popular renewable energy sources since; it is clean, inexhaustible, requires little maintenance, offers 
flexibility of installation (rooftop), and its cost is decreasing [3], [4]. Topologies, control strategies, and operational objectives of grid-connected PV systems for efficient operations are discussed in details by many researchers in literature [5]-[8]. Voltage Source Inverter (VSI) for single-phase PV grid-tied system is found to be one of the preferrable methods of integrating or interfacing small ratings PV units (power output under $10 \mathrm{~kW}$ ) into the grid [5], [9], [10].

Although integrating single-phase PV systems with the grid has its advantages and has been on the rise due to governments support and its economic benefits, nonetheless; the widespread of PV systems poses more challenging issues for the distribution system operator and the entire grid [11]. The drawback of gridtied PV systems is that with the use of inverters as an interface, it leads to many problems regarding the safety, efficiency of the grid, stability (including voltage and frequency stability), increased level of harmonics, and poor power factor of the entire system [12]. Therefore, specific grid requirements regarding the penetration of grid-connected PV systems in low voltage networks have been put forward as outlined in EN 50160 and IEEE1547 standards. Those standards specify that grid-connected PV systems must comply with: the levels of Total Harmonic Distortion (THD), power factor, level of injected DC current, and voltage and frequency range [3], [11], [13].

To find solutions to overcome the challenges associated with grid-connected PV systems, researchers proposed various techniques and solutions concerning issues such as: efficient implementation of Maximum Power Point Tracking (MPPT) algorithms with the aim to supply maximum active power to the grid [10], [14]; synchronization with grid and estimation of grid frequency in single phase PV systems [15][17]; and applications of advanced control techniques to regulate active and reactive power flow to grid [18][21]. However, most of the work presented in literature did not address in details the different scenarios of power flow in a grid-connected PV system while being simultaneously connected to a local load, and operating at different levels of solar irradiances.

In this work, an Inverter Power Management System (IPMS) for a grid-connected PV system is developed. The main contribution of this paper is the development of an IPMS that regulates the power flow between the grid and the PV system in the presence, or absence of local loads while taking into consideration the operation at different levels of solar irradiances. The IPMS developed in this paper has also been tasked to regulate the amount of reactive power to be injected or absorbed by the inverter in order to meet grid standards in terms of power factor and current THD requirements.

The work presented in this paper is organized as follows: Section 2 presents research method and theoretical background of the proposed system, Section 3 presents the simulation results (using MATLAB/Simulink) of the system under investigation, and lastly, the conclusion of the system performance is presented in section 4 .

\section{RESEARCH METHOD}

Figure 1 shows the topology of the PV grid-connected converter system considered in this work. It includes a single-phase inverter (with unipolar PWM switching) fed by PV system, an LCL filter, a local load, utility grid equivalent model, and the inverter control unit embedded in the IPMS.

\subsection{The power calculator and MPPT algorithm}

In Figure 1, the reference power $\left(P^{*}\right)$ represents the amount of power available from PV panels, and it is calculated using Maximum Power Point Tracking (MPPT) when the system is operating with no reactive power compensation, i.e. at unity power factor. The active and reactive powers (PQ) calculator will examine the reactive power compensation requirements by the grid and the load; and if there is a reactive power demand (i.e. $Q \neq 0$ ), then the VA capacity of the inverter together with the power factor requirements will determine the amount of real power supplied to the grid and load. Derating of real power may become a requirement if the VA capacity of the inverter is exceeded. On the other hand, if there is no reactive power compensation requirement (i.e. $Q=0$ ), then MPPT operation is maintained. In either case, if $P^{*}$ exceeds the local load power demands $\left(P_{L}\right)$, then the balance power will be injected into the grid $\left(P_{g}\right)$.

The amount of grid injected power $\left(P_{g}\right)$ will be compared with half the rated power of the inverter $\left(0.5 P_{\text {rated }}\right)$, and if $P_{g}>0.5 P_{\text {rated }}$, then reactive power compensation might become a requirement as in IEC61727 standards [6]. Therefore, in the proposed PQ calculator the amount of power supplied by the converter can be optionally adjusted (according to grid conditions e.g. voltage and frequency) to allow reactive power injection, if required. The amounts of active and reactive power supplied to grid are controlled to satisfy the power factor constraints mandated by grid standards. At all the times, the PQ calculator will ascertain that total apparent power supplied to the load and the grid doesn't exceed the inverter's rating in accordance with (1): 


$$
S_{\text {in }}=S_{l}+S_{g}
$$

Where $S_{i n}$ is the inverter available VA capacity, $S_{l}=\sqrt{P_{l}^{2}+Q_{l}^{2}}$ : is the load VA demand, and $S_{g}=$ $\sqrt{P_{g}^{2}+Q_{g}^{2}}$ : is surplus VA supplied to the grid. For example, to maintain the grid power factor at 0.9 when $P_{g}>0.5 P_{\text {rated }}$, and while reactive power compensation is required, then:

$$
Q_{g}^{*}=0.484 P_{g}^{*}
$$

Where $P_{g}^{*}$ and $Q_{g}^{*}$ are respectively, the commanded grid active and reactive powers, Therefore, the amount of active power to be delivered to the grid can be adjusted or de-rated (considering the inverter's VA rating, $\left.S_{\text {rated }}\right)$ as,

$$
P_{g}^{*}=\frac{P_{M P P}-\sqrt{P_{l}^{2}+Q_{l}^{2}}}{\sqrt{1.234}}
$$

Where $P_{M P P}$ is the maximum power available from the PV system. Based on (2) and (3), the inverter's commanded input active power $\left(P_{i n}^{*}\right)$ and reactive power $\left(Q_{i n}^{*}\right)$ are determined as,

$$
\begin{aligned}
& P_{i n}^{*}=P_{l}+P_{g}^{*} \\
& Q_{i n}^{*}=Q_{l} \pm Q_{g}^{*}
\end{aligned}
$$

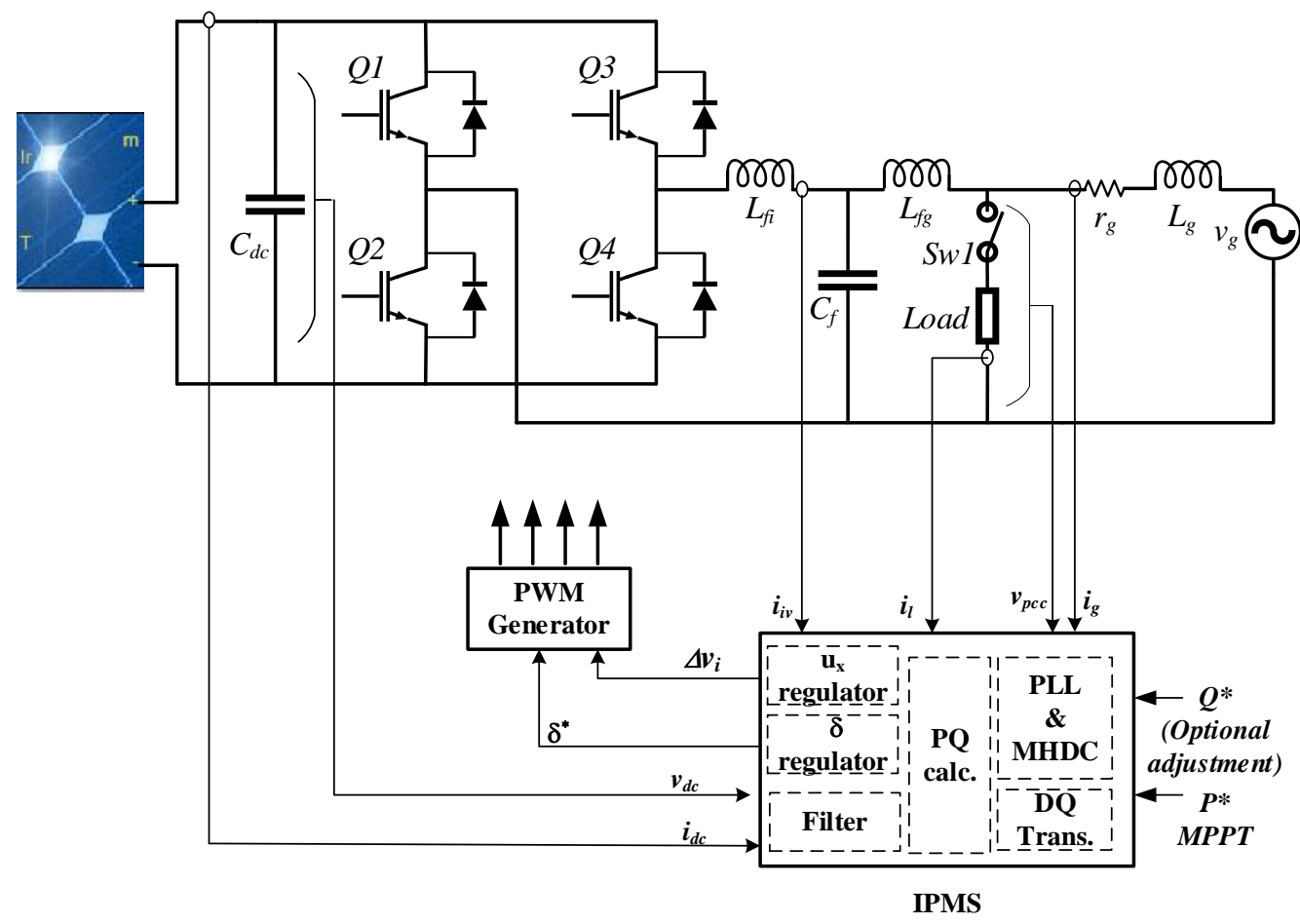

Figure 1. Structure of the proposed single-phase grid-connected PV system

On the other hand, if the amount of power supplied to the grid is less than the inverter's half capacity i.e. $P_{g}<0.5 P_{\text {rated }}$, then the reactive power compensation is turned off, and the amount of reactive power supplied by the inverter is only limited to meet the local load demands. Note that the grid reactive power compensation can be optionally set to zero $\left(Q_{g}^{*}=0\right)$, even when $P_{g}>0.5 P_{\text {rated }}$, and this corresponds to $P_{g}^{*}=P_{M P P}$ in case of MPPT operation is required. 
To guarantee that maximum power is being extracted from a PV array and transferred to grid/ load system at all times, MPPT control algorithms are usually used for this purpose. In recent years, a large number of MPPT techniques have been proposed for tracking the maximum power point. Proposed techniques vary in terms of complexity, accuracy, efficiency, and hardware requirements. Classical MPPT techniques such as; Perturb and Observe (P\&O), Incremental Conductance (IC), and Ripple Correlation (RC) methods are deemed to be suitable and practical [22]. A comprehensive evaluation of MPPT under the EN 50530 dynamic test procedure can be found in [23].

In this study, $\mathrm{P} \& \mathrm{O}$ technique is used to the track the maximum power point of a PV array. The array used in this study is conFigured using one parallel string with 14 series-connected modules per string. The I$\mathrm{V}$ and P-V characteristics of the PV array for different levels of solar irradiance and under a constant temperature of $25^{\circ} \mathrm{C}$ are shown in Figures 2(a) and 2(b), respectively.

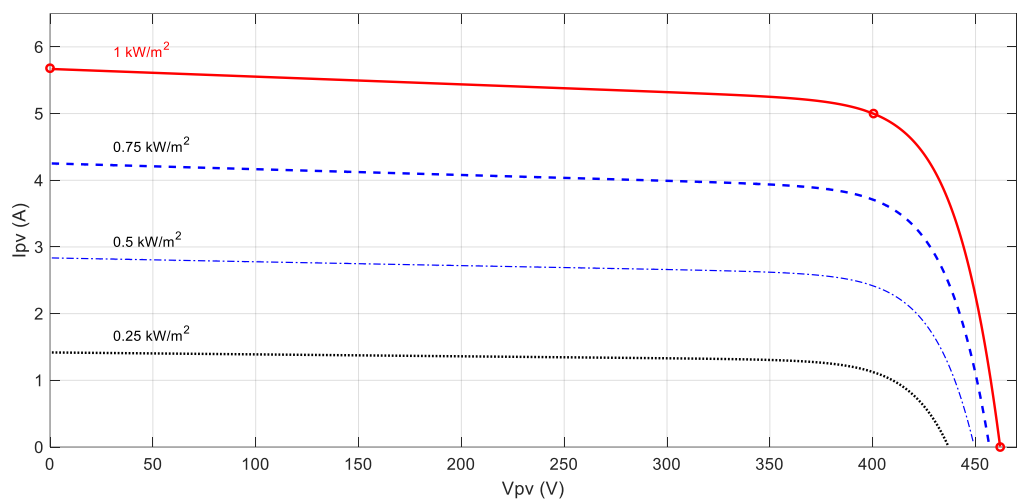

(a)

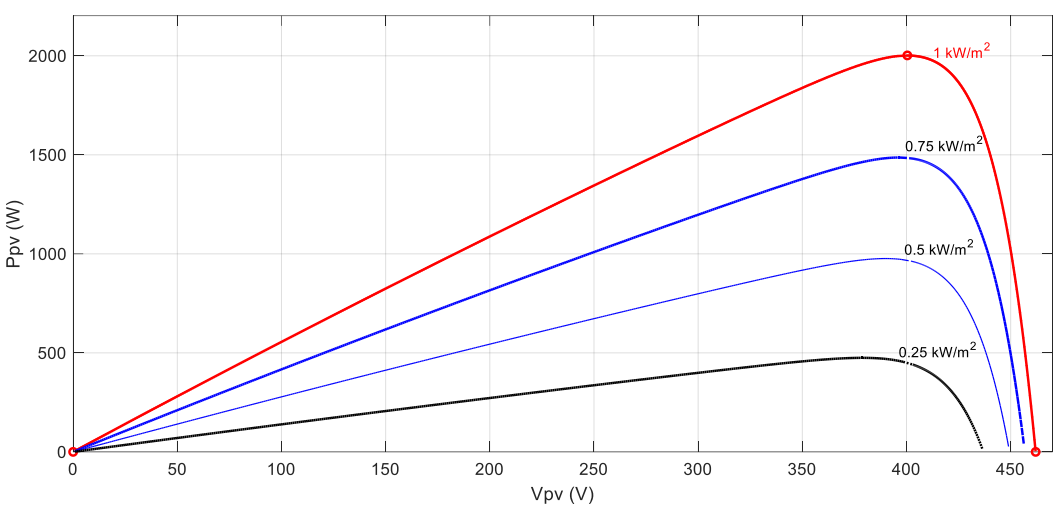

(b)

Figure 2. Photovoltaic array characteristics: (a) I-V characteristics for varying irradiance (b) P-V characteristics for varying irradiance

The MPPT will be maintained for unity PF operation, however, if the reactive power compensation is required, then the total apparent power (VA) demand is examined to ensure that it doesn't exceed the inverter's rating. In case the VA demands exceed the inverter's ratings, the maximum power point operation is de-rated as in (3) and the MPPT algorithm is disabled; otherwise, operation is maintained at MPPT. It has to be emphasized that that derating will only occur if the PV array is subjected to maximum solar irradiance, and thus the inverter is operating near full capacity. Researchers in [24] proposed an advanced Power Reserve Control (PRC) that enables the PV system to operate at point with a curtailed power level in order to realize potential grid support.

Figure 3 show the Simulink implementation of the MPPT using P\&O technique and the DC link voltage regulator. The reference voltage for the $\mathrm{DC}$ link voltage can either be obtained from the $\mathrm{P} \& \mathrm{O}$ algorithm for operation at MPPT, or from a predetermined fixed DC reference value for de-rating of the PV power. The DC link voltage regulator is a PI regulator with parameter $K_{p D C}=200$, and $K_{i D C}=12$. 


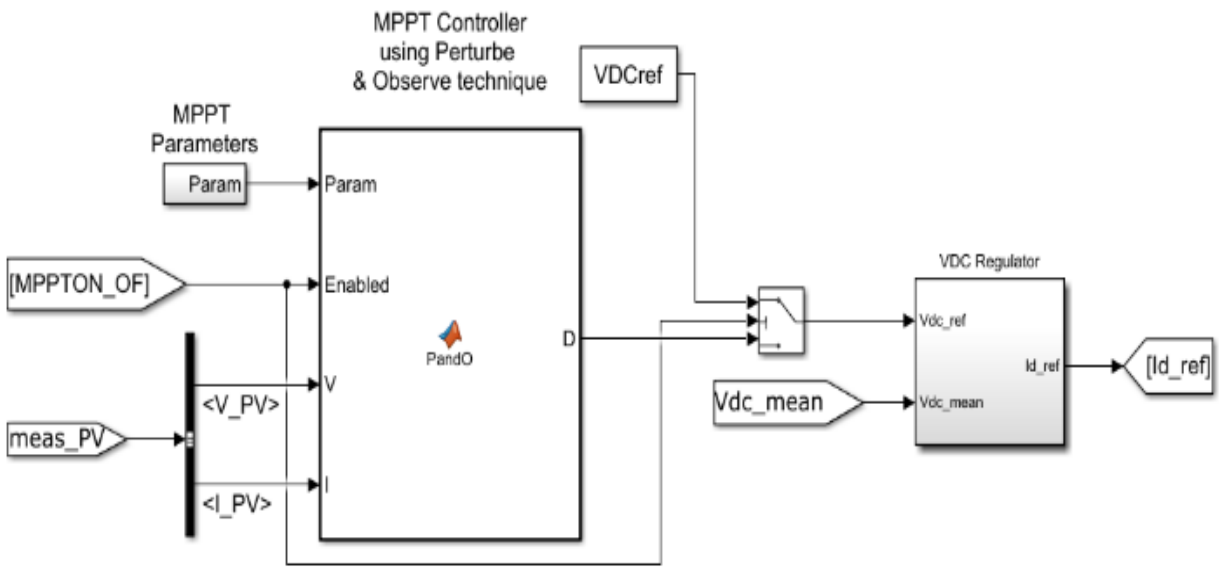

Figure 3. Simulink implementation of MPPT and DC link voltage controller

\subsection{Power angle $(\delta)$ regulator}

The active power from the inverter to the grid in steady state (with inductor resistances ignored) is given as [13],

$$
P=\frac{V_{i} V_{g}}{2 X_{t}} \sin (\delta) \approx \frac{V_{i} V_{g}}{2 X_{t}} \delta
$$

Where $V_{i}$ and $V_{g}$ are respectively the peak voltage of inverter and grid, $X_{t}$ is the reactance of the line total inductance, $\delta$ is the power angle and for small $\delta, \sin (\delta) \approx \delta$. The inverter power angle is adjusted using a PI regulator that operates on the error between the reference power $\left(P_{\text {ref }}\right)$ and the inverter's output power $\left(P_{o}\right)$. The DC link current is filtered and regulated by controlling the power angle $(\delta)$ to track the reference power command as shown in Figure 4.

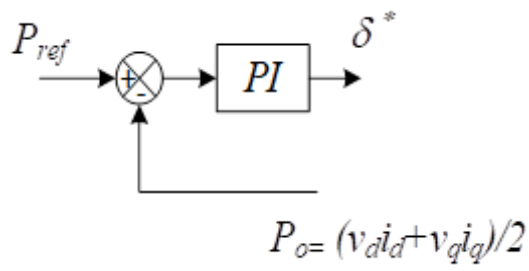

Figure 4. Power angle regulator.

With the assumption that the inverter is lossless, the instantaneous power balance at the input and output sides of the inverter can be expressed as,

$$
p_{D C}(t)=p_{A C}(t)
$$

Where $p_{D C}(t)$ and $p_{A C}(t)$ are the inverter's instantaneous input DC and output AC power. Using the space vector representation of the circuit in Figure 5; then (7) can be written as,

$$
v_{D C}(t) i_{D C}(t)=\frac{v_{i D}(t) i_{i D}(t)+v_{i Q}(t) i_{i Q}(t)}{2}
$$

Where: $v_{i D}, v_{i Q}$ and $i_{i D}, i_{i Q}$ : are respectively, the direct (D) and quadrature (Q) components of the inverter voltage and current space vectors. 


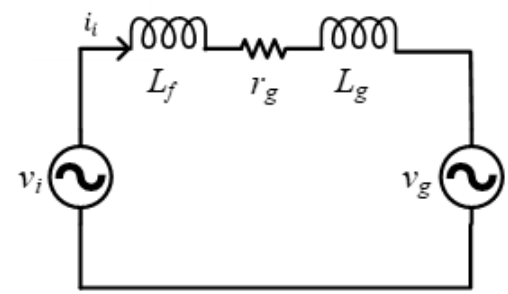

(a)

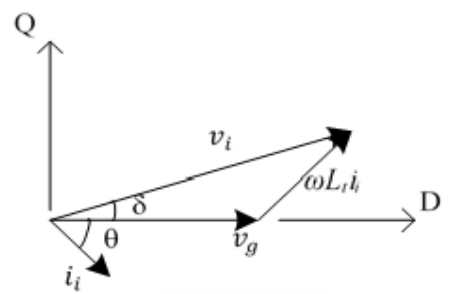

(b)

Figure 5. Model of space vector representation of grid-connected inverter: (a) Equivalent circuit of grid connected inverter, and (b) Space vector representation.

From Figure 5(a), the state space equations of the inverter voltages and currents can be expressed as,

$$
v_{i}(t)=v_{g}(t)+r_{g} i_{i}(t)+(\rho+j \omega) L_{t} i_{i}(t)
$$

where $\rho=d / d t$ (is the differential operator), $\omega$ is angular frequency of the grid, rg: is the line equivalent resistance, $L_{t}=L_{f}+L_{g}$ : is the line total inductance, $i_{i}(t)$ : is the inverter current vector, $v_{g}(t)$ and $v_{i}(t)$ : are respectively the grid and inverter voltage space vectors. The DQ components of the voltages and currents can then be obtained as,

$$
\begin{aligned}
& v_{i D}(t)=v_{g D}(t)+\left(\rho L_{t}+r_{g}\right) i_{i D}(t)-\omega L_{t} i_{i Q}(t) \\
& v_{i Q}(t)=v_{g Q}(t)+\left(\rho L_{t}+r_{g}\right) i_{i Q}(t)+\omega L_{t} i_{i D}(t)
\end{aligned}
$$

If the DC link voltage in (8) is assumed to be constant, then (8) can be linearized around an operating point as,

$$
\Delta i_{D C}(t)=\frac{\Delta v_{i D}(t) i_{i D o}+v_{i D o} \Delta i_{i D}(t)+\Delta v_{i Q}(t) i_{i Q o}+v_{i Q o} \Delta i_{i Q}(t)}{2 V_{D C}}
$$

If the grid is assumed constant (voltage and frequency), and the inverter voltage is sinusoidal; then linearizing (10) and (11) for a small change in the power angle, and substituting in (8) results in a linear model that relates the response of the DC-link current to the change in the power angle as given in the transfer function in (13),

$$
\frac{I_{D C}(s)}{\delta(s)}=\frac{K}{\left(s+\frac{r g}{L_{t}}\right)^{2}+\omega^{2}}
$$

Where, $\mathrm{s}$ is the Laplace operator, $K=\frac{\omega V_{i o}^{2}}{2 V_{D C} L_{t}}$ and it depends on the inverter parameters, and $V_{i o}$ is the inverter nominal voltage.

\subsection{Reactive power regulator}

The reactive power flow between the inverter and the grid-load system is controlled by regulating the inverter output voltage. Again, if the power angle is small, the reactive power flow between the inverter and the grid-load system is given as [13],

$$
Q=\frac{V_{g}\left(V_{i} \cos \delta-V_{g}\right)}{2 X_{t}} \approx \frac{V_{g}}{2 X_{t}}\left(V_{i}-V_{g}\right)
$$

In steady state, from (14), the reactive power flow is related to the voltage difference between the inverter and the grid. The reactive power regulation scheme is carried out by regulating the quadrature component of the inverter current $\left(i_{i Q}\right)$, to track the reference value $\left(i_{i Q}^{*}\right)$, which corresponds to $\left(Q_{\text {ref }}\right)$; as calculated from the load/grid reactive power demand in (5). The regulator will continuously adjust the inverter output voltage by controlling the modulation index $\left(\Delta v_{i}\right)$ according to the scheme shown in Figure 6. 


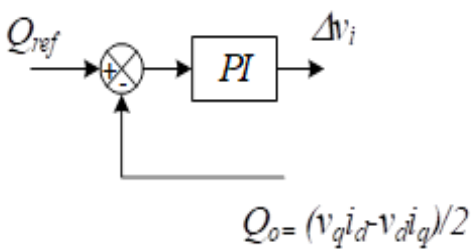

Figure 6. Inverter voltage regulation.

The reactive power response of the inverter to a change in the inverter output voltage can be written in a similar manner as in the previous section. However, this time, taking the instantaneous reactive power of the inverter in the DQ reference frame, and linearizing around operating voltage point, the transfer function can be written as,

$$
\frac{\Delta Q_{i}(s)}{\Delta V_{i}(s)}=\frac{K_{1}}{\left(s+\frac{r g}{L_{t}}\right)^{2}+\omega^{2}}
$$

Where $K_{1}=\frac{\omega V_{i o}}{L_{t}}$ and it depends on the inverter parameters. The parameters of both PI controllers (used in the inverter power angle and voltage regulation) were obtained using the PI tuner provided by Simulink.

\subsection{LCL filter design}

An LCL filter is used to reduce the high-order current harmonics produced by the inverter at switching frequency. The LCL filter is designed using the methodology presented in [25]. The maximum value of the filter total inductance $\left(L_{t f \max }\right)$ is given as,

$$
L_{t f \max }=\frac{v_{g}^{2}}{2 \pi f_{g} P} \times 10 \%
$$

Where $f_{g}$ is the grid frequency, $v_{g}$ : is the grid voltage, and $P$ is the rated power of the inverter. The filter total inductance is split into two parts: one at the inverter side $\left(L_{f i}\right)$, and the other one at the grid side $\left(L_{f g}\right)$. The ratio between the two inductors depends on the design parameters such as the harmonic attenuation ratio, filter and inverter parameters (filter capacitor, $C_{f}$; Switching frequency, $f_{s w} \ldots$ ) as specified in [23].

\section{RESULTS AND DISCUSSION}

A simulation study using MATLAB/Simulink has been carried out to demonstrate the effectiveness of the proposed control scheme in managing active and reactive power flow from PV inverter to the local load and grid system. The parameters of the PV inverter system are given in Table 1. Since the solar irradiation varies throughout the day; the PV inverter system has been simulated for full and low levels of solar irradiance.

Table1. Secifications adopted for the simulated grid-connected PV-inverter

\begin{tabular}{cccc}
\hline Parameter & Value & Parameter & Value \\
\hline Inverter rated power $\left(S_{\text {rated }}\right)$ & $2 \mathrm{kVA}$ & PWM Switching frequency $\left(f_{s}\right)$ & $10 \mathrm{kHz}$ \\
Filter inductances $\left(L_{f i}\right),\left(L_{f g}\right)$ & $13.5 \mathrm{mH}, 6 \mathrm{mH}$ & Grid voltage $V_{g}(\mathrm{rms})$ & $230 \mathrm{~V}$ \\
Grid side inductance $\left(L_{f g}\right)$ & $3 \mathrm{mH}$ & Grid frequency $\left(f_{g}\right)$ & $50 \mathrm{~Hz}$ \\
Grid side resistance $\left(f_{g}\right)$ & $2.5 \Omega$ & Inverter input DC voltage $\left(V_{D C}\right)$ & $400 \mathrm{~V}$ \\
Filter capacitor $\left(C_{f}\right)$ & $1.0 \mu \mathrm{F}$ & Power angle PI regulator $K_{p}, K_{i}$ & $0.002,2.5$ \\
DC link Capacitor $\left(C_{d c}\right)$ & $2000 \mu \mathrm{F}$ & Reactive power PI regulator $K_{p}, K_{i}$ & $0.01,5$ \\
\hline
\end{tabular}

\subsection{Full solar irradiance}

In this mode of operation, the inverter system receives the rated power from the PV system, and therefore, the inverter can deliver near full or rated power to the grid and/or the local load. Figure 7 shows the current, voltage, active and reactive power, and THD of the grid current. Figure 7(a) shows the waveforms 
for the inverter, grid and load current, and the voltage at the PCC. The subplot in Figure 7(a) shows a magnified view of the voltage and current waveforms. The active and reactive power flows are depicted in Figure 7(b) and (c) respectively. The PV system is simulated for a total duration of 2 seconds, divided into 5 intervals (each of $0.4 \mathrm{sec}$ duration) to simulate 5 different operating conditions as explained below:

Area 1: $(0 \leq \mathrm{t}<0.4 \mathrm{~s})$; reactive power compensation is OFF and local load is OFF (disconnected from the PCC). In this mode the inverter is supplying its maximum power to the grid, and hence operating at unity PF emulating the MPPT operation. In area 1, Figure 7(a) shows that the inverter current is in phase with the voltage at the PCC; Figure 7(b) shows maximum real power is being supplied to the grid; and Figure 7(c) shows zero reactive power is being delivered to the grid. The analysis of the current THD in Figure 8(a) shows that it is still in compliance with various international standards. Area 2 : $(0.4 \leq \mathrm{t}<0.8 \mathrm{~s})$; reactive power compensation is ON (leading PF) and local load is OFF. The reactive power compensation is selected to operate the inverter at 0.9 leading PF; thus, inverter is supplying real and reactive power to the grid. It can be seen during this mode of operation the inverter's real power has been de-rated, as in Figure 7(b), to accommodate the reactive power supplied to the grid, as in Figure 7(c).

Area 3: $(0.8 \leq \mathrm{t}<1.2 \mathrm{~s})$; reactive power compensation is $\mathrm{ON}$ (lagging PF) and local load is OFF. The reactive power compensation is selected to operate the inverter at 0.9 lagging PF; thus, the inverter is supplying real power and absorbing reactive power. It can be seen during this period of time the inverter has de-rated its real output power to allow absorption of reactive power. Area 4: $(1.2 \leq \mathrm{t}<1.6 \mathrm{~s})$; reactive power compensation is ON and local load is ON. During this period the reactive power compensation will not have any effects on the inverter operation since the inverter's full capacity is being utilized to supply the local load demands (active and reactive power) and no power is delivered to the grid. Area 5: $(1.6 \leq \mathrm{t}<2.0 \mathrm{~s})$; the operation during this time interval is simulated when the inverter is supplying simultaneously the grid and the local load. The local load in area 5 is stepped down to approximately half its value in area 4, thus the inverter will supply power to the grid and local load simultaneously. Figures. 8(a), 8(b), 8(c), and 8(d) depict the THD in the grid current for operation in areas 1,2, 3 and 5, respectively. The current THD for full irradiation level stayed within the prescribed limits by the international standards.

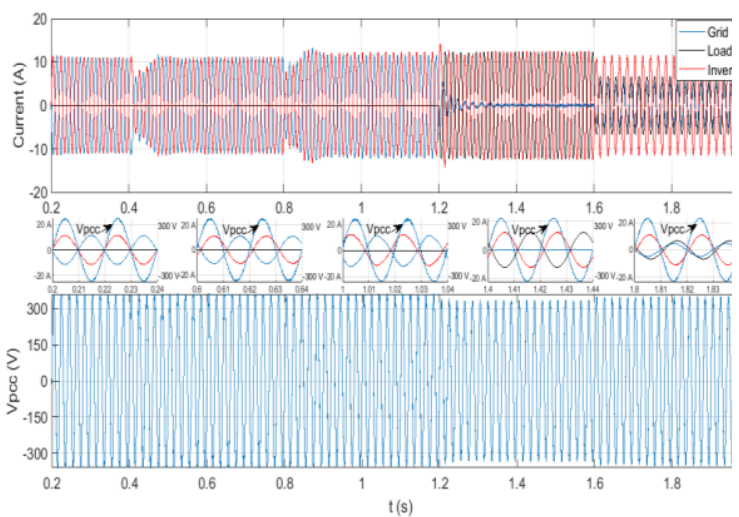

(a)

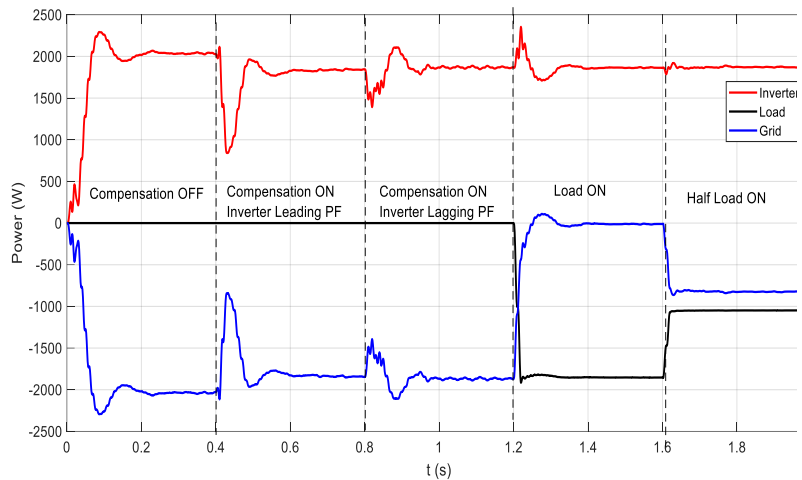

(b)

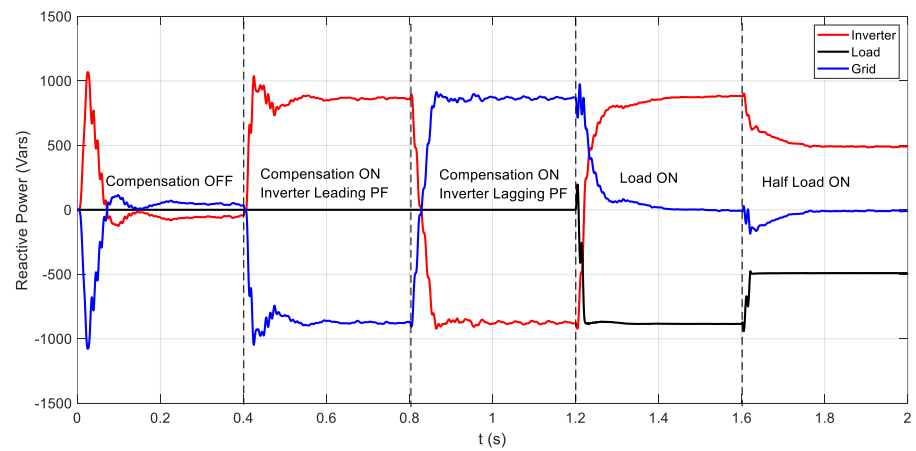

(c)

Figure 7. Simulation results of grid-connected PV inverter operating under full solar irradiance: (a) Current and voltage signals, (b) active power, (c) reactive power 


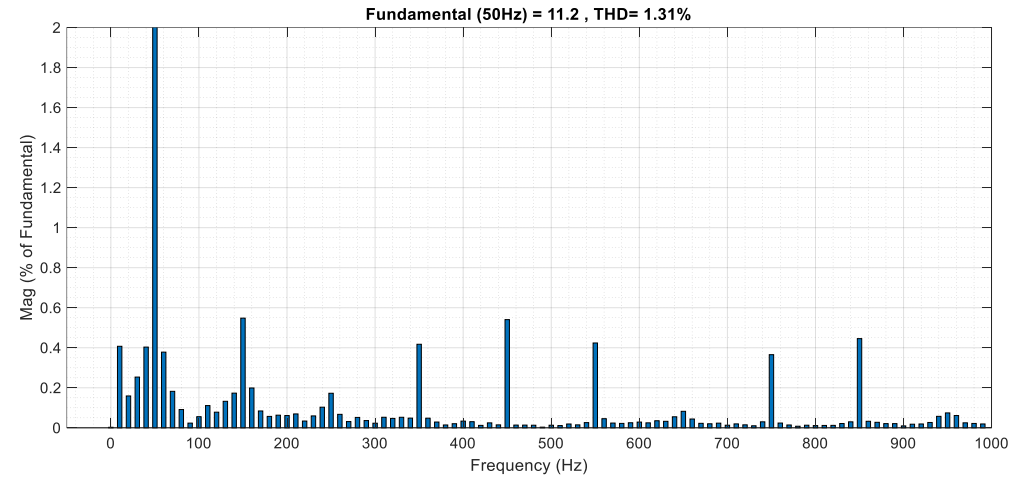

(a)

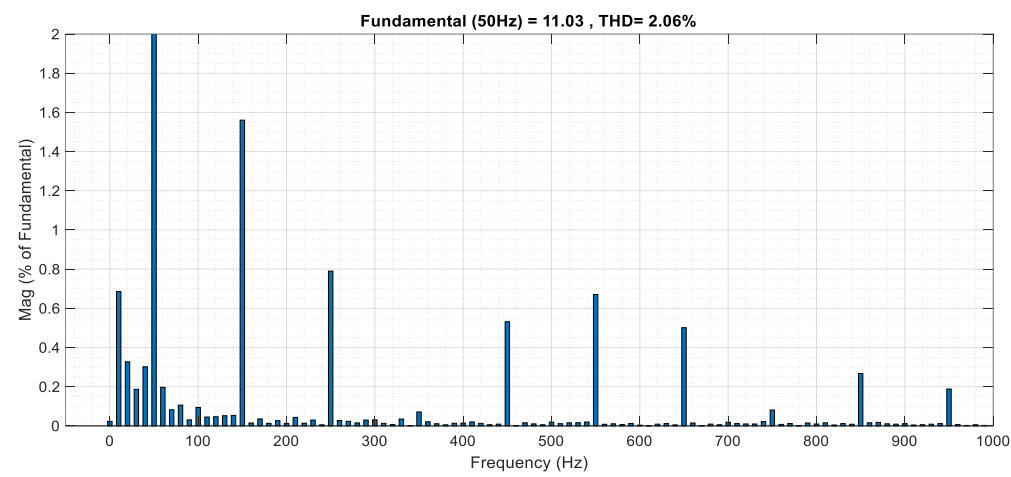

(b)

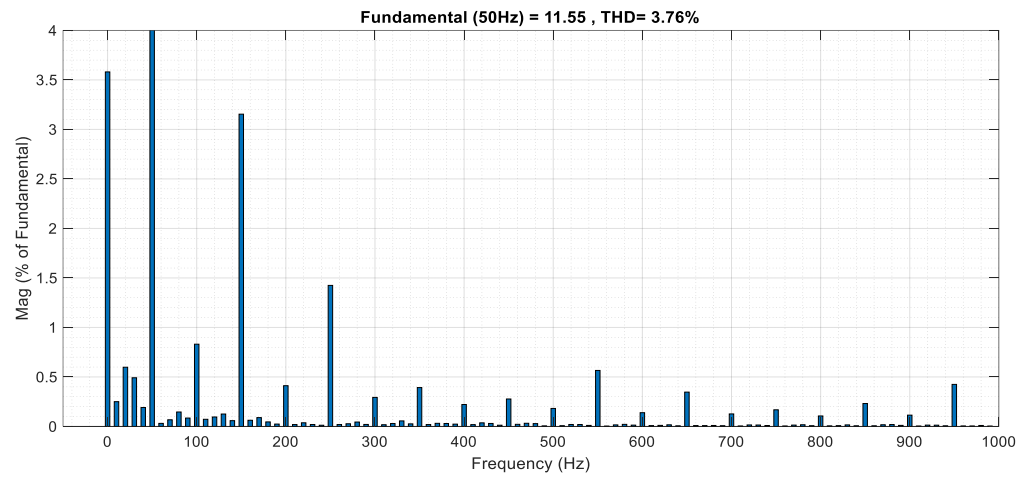

(c)

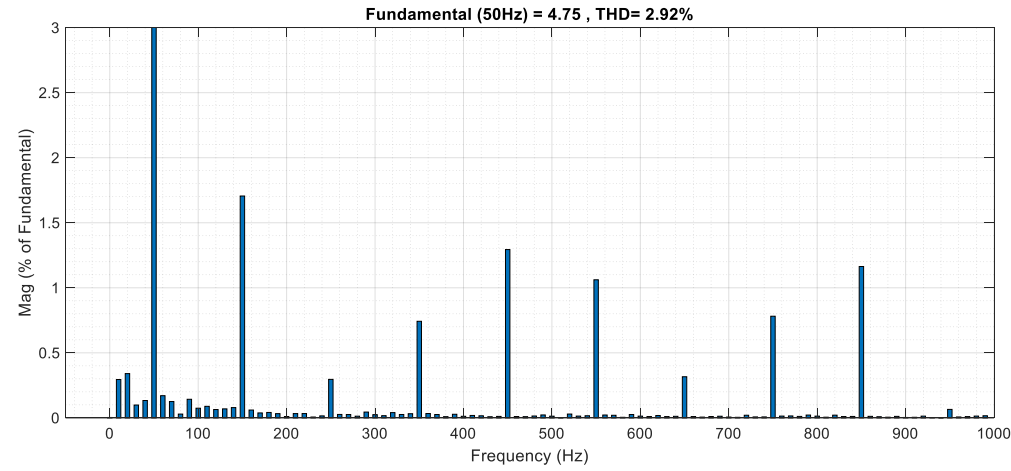

(d)

Figure 8. Simulation results of grid-connected PV inverter operating under full solar irradiance current THD for (a) unity, (b) 0.9 leading, (c) 0.9 lagging PF operation, (d) power supplied to grid and load 


\subsection{Low solar irradiance}

In the second case, the simulation is carried out to resemble a cloudy day or weak solar irradiance as depicted in Figure 9. The level of irradiation is set to $40 \%$, thus the inverter is operating below one-half its rated capacity. However, since the inverter is operating below one-half the rated capacity, the reactive power compensation will have no effects on the inverter power, i.e. no de-rating of the real power and the reactive power supplied to the grid is zero. The PV inverter operation has been divided into three areas, such as;

Area 1: $(0 \leq \mathrm{t}<1.2 \mathrm{~s})$; reactive power compensation is ON/OFF and the local load is OFF. During this period of time the inverter supplies only real power to the grid; since the power supplied to the grid is less than one-half the inverter's rated capacity, no reactive power is supplied to the grid. Figure 9(a) shows that the inverter current waveform is in phase with the voltage at the PCC. The active and reactive power flows are shown respectively in Figures 9(b) and 9(c).

Area 2: $(1.2 \leq \mathrm{t}<1.6 \mathrm{~s})$; during this mode, the inverter delivers all its available real power to the load, and the grid supplies the balance of the load real power demands. Since the inverter's capacity is not fully utilized, the inverter supplies all the reactive power demanded by the load, and hence the grid will be operating at unity PF. Note must be taken that the inverter in this mode is operating at a PF below 0.8; which implies that maximum ratio of the reactive power (Vars) to the rated apparent power (VA) should be $100 \%$. This also means that a larger cable may need to be sized if it is anticipated that the inverter will be operating with a lagging power factor [26].

Area 3: $(1.6 \leq \mathrm{t}<2.0 \mathrm{~s})$; the operation during this time interval is simulated when the load is being supplied simultaneously by both the inverter and the grid since the amount of real power available from the PV system is not sufficient to supply the local load power demand.

Figure 9(d) depicts the THD in the grid current when the PV system is operating at approximately $40 \%$ of its rated capacity. It can be observed that the current THD slightly exceeds the prescribed limits (>5\%); which is one of the major drawbacks reported for low levels of solar irradiance [27], [28].

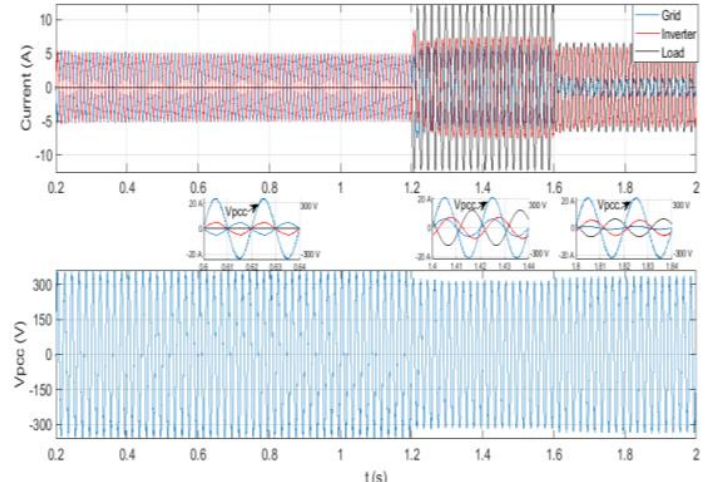

(a)

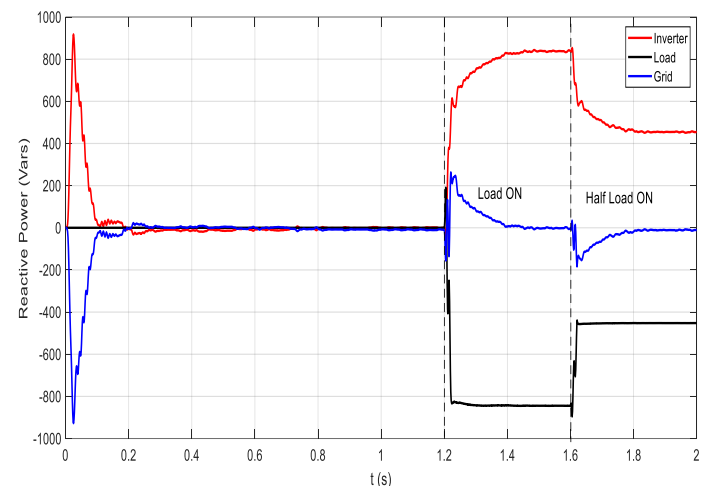

(c)

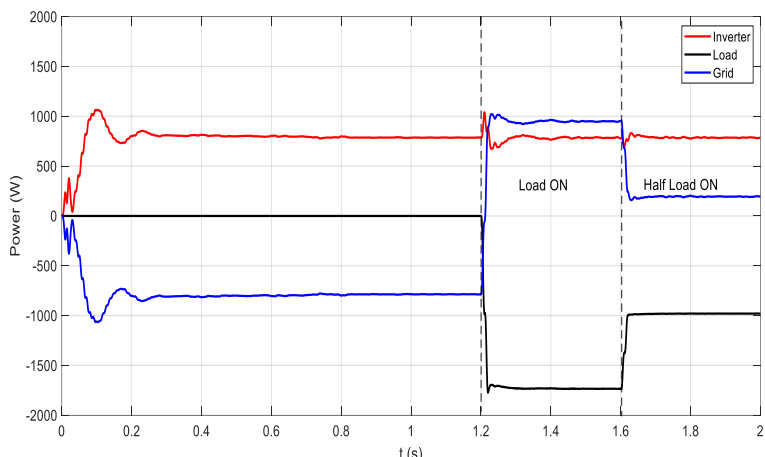

(b)

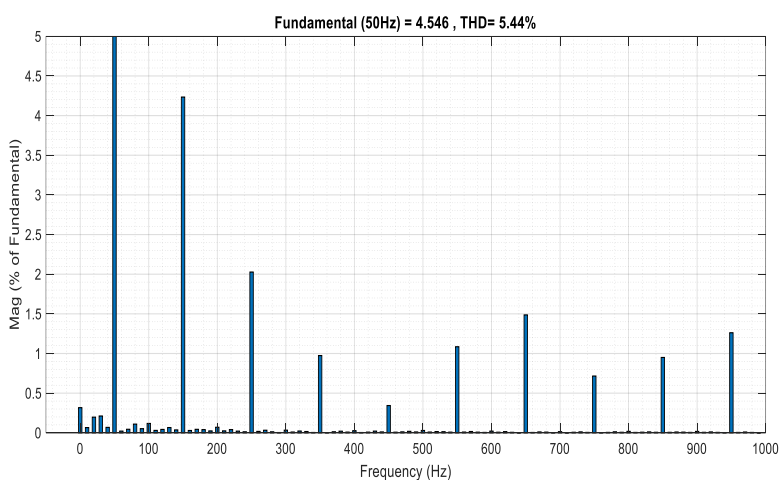

(d)

Figure 9. Simulation results of grid-connected PV inverter operating under 40\% solar irradiance: (a) Current and voltage signals, (b) active power, (c) reactive power, current THD for (d) unity PF $40 \%$ load operation 


\section{CONCLUSION}

In this study the operation of a single-phase grid-connected PV inverter system has been examined while simultaneously being connected to a local load at the PCC. Two simple PI controllers have been used to directly regulate inverter's active and reactive power flow. The inverter has been conFigured to operate with a flexible reactive power compensation mode; where real power supplied to the grid, when $50 \%$ of the rated capacity of the inverter exceeds, can be delivered optionally at unity, 0.9 leading or lagging PF operation. This compensation scheme becomes very useful when it is triggered by the voltage level at the PCC, or alternatively used to comply with reactive power demands set by the grid operator.

The simulation results showed that when the solar irradiance is at full level, the THD of the gridinjected current conforms to required standards. However, for low levels of solar irradiance, the THD in the grid-injected current increases beyond the prescribed limits. This may require grid-connected PV systems when injecting power at low level of solar irradiance to either use better filtering techniques or even disconnecting the PV system from the grid. An alternative that can be explored in future research is to maintain the fundamental component of the grid-injected current at higher values by increasing the amount of reactive power injected into the grid. By increasing the fundamental component of the injected current, the THD of the current will be reduced (since THD is inversely proportional with fundamental component of the current). However, this proposition comes at the expense of operating the grid at lower PF, which has to be weighted from economical point of view against the other alternatives (turning off the PV, injecting current with higher values of THD, or sizing the cables) when the solar irradiance is at low levels.

\section{ACKNOWLEDGEMENTS}

The researchers are grateful to the Applied Science Private University, Amman, Jordan for the full financial support grated to this research project.

\section{REFERENCES}

[1] K. Cabana, et al., "Voltage sensitivity analysis to determine the optimal integration of distributed generation in distribution systems," International Journal of Electrical and Computer Engineering (IJECE), vol. 9, no. 1, pp. 5565, 2019, doi: 10.11591/ijece.v9i1.pp55-65.

[2] R. S. Ravi Sankar, et al., "Adaptive fuzzy PI current control of grid interact PV inverter," International Journal of Electrical and Computer Engineering (IJECE), vol. 8, no. 1, pp. 472-482, 2018, doi: 10.11591/ijece.v8i1.pp472482.

[3] V. Beena, et al., "Active and reactive power control of single phase transformerless grid connected inverter for distributed generation system," International Journal of Applied Engineering Research, vol. 13, no. 1, pp. 150-157, 2018.

[4] P. Aurobinda, et al., "Single-phase photovoltaic inverter control for grid connected system," Indian Academy of Sciences Sadhana, vol. 41, pp. 15-30, 2016.

[5] Y. Yang and F. Blaabjerg, "Overview of single-phase grid-connected photovoltaic systems," Electric Power Components \& Systems, vol. 43, no. 12, pp. 1352-1363, 2015, doi: 10.1080/15325008.2015.1031296.

[6] S. Sundaram, et al., "Grid connected photovoltaic systems: Challenges and control solutions- A potential review," International Journal of Electronics and Electrical Engineering, vol. 4, no. 6, pp. 463-473, 2016, doi: 10.18178/ijeee.4.6.463-473.

[7] T. Jalilzadeh, et al., "Analytical study and simulation of a transformer-less photovoltaic grid-connected inverter with a delta-type tri-direction clamping cell for leakage current elimination," The International Journal for Computation and Mathematics in Electrical and Electronic Engineering, vol. 37, no. 2, pp. 814-831, 2018, doi: 10.1108/COMPEL-03-2017-0114.

[8] M. Alomari, et al., "Solar photovoltaic power forecasting in Jordan using artificial neural networks," International Journal of Electrical and Computer Engineering, vol. 8, no. 1, pp. 497-504, 2018.

[9] S. Golestan, et al., "A D-Q synchronous frame controller for single phase inverters," $2^{\text {nd }}$ Power Electronics, Drive Systems and Technologies Conference. University of Tehran, 16-17 February 2011, Tehran, Iran.

[10] O. M. Arafa, et al., "Realization of single-phase single-stage grid connected PV system," Journal of Electrical Systems and Information Technology, vol. 4, pp. 1-9, 2017.

[11] Y. Yang, et al., "Reactive power injection strategies for single-phase photovoltaic systems considering grid requirements," Proceedings of the 29th Annual IEEE Applied Power Electronics Conference and Exposition, Fort Worth, TX, United States, 16-20 March 2014.

[12] S.-H. Ko, et al., "A grid-connected photovoltaic system with direct coupled power quality control," $32^{\text {nd }}$ Annual Conference of the IEEE Industrial Electronics Society, Paris, France, 7-10 November 2006.

[13] B. S. Sotirios, et al., "ANN and fuzzy logic controller design for hybrid wind/PV system connected to MV distribution grid," International Journal of Energy Sector Management, vol. 2, no. 4, pp. 499-520, 2008.

[14] M. A. Mohaned, et al., "Implementation of MPPT algorithm for single-stage grid connected photovoltaic system using incremental conductance method," Journal of Renewable energy and Sustainable Development (RESD), vol. 4 , no. 2 , pp. 57-64, 2018 
[15] S. Golestan and J. M. Guerro, "Conventional synchronous reference frame phase-locked loop is an adaptive complex filter," IEEE Transactions on Industrial Electronics, vol. 62, pp. 1679-1682, 2015.

[16] L. Hadjidemetriou, et al., "A synchronization scheme for single-phase grid-tied inverters under harmonic distortion and grid disturbances," IEEE Transactions on Power Electronics, vol. 32, pp. 2784-2793, 2017.

[17] E. Radwan, et al., "Modified phase locked loop for grid connected single phase inverter," International Journal of Electrical and Computer Engineering, vol. 9, no. 5, pp. 3934-3943, 2019,

[18] G. M. Tina and G. Celsa, "Active and reactive power regulation in grid-connected PV systems," $50^{\text {th }}$ International Universities Power Engineering Conference, UPEC 2015, Stoke on Trent, pp. 1-6, 2015.

[19] Y. Sravanthi and P. Sujatha, "Fuzzy logic controller for low voltage ride through capability improvement of grid connected photovoltaic power plants," International Journal of Advanced Research Electr. Electron. Instrum. Eng, vol. 6, pp. 7213-7226, 2017.

[20] J. Fei, and Y. Zhu, "Adaptive fuzzy sliding control of single-phase PV grid-connected inverter," PLOS ONE, vol. 12, no. 8, e0182916, 2017.

[21] W. Zhang, et al., "A proportional resonant controller tuning method for grid connected power converters with LCL+trap filter, " $3^{\text {rd }}$ International Conference on Renewable Energy Research and Applications, Milwakuee, USA, 2014.

[22] M. Hlaili and H. Mechergui, "Comparison of different MPPT algorithms with a proposed one using a power estimator for grid connected PV systems," International Journal of Photoenergy, vol. 2016.

[23] X. Li, et al., "A comparative study on photovoltaic MPPT algorithms under EN50530 dynamic test procedure," IEEE Transactions on Power Electronics, September 2020.

[24] X. Li, et al., "A novel sensorless photovoltaic power reserve control with simple real-time MPP estimation," IEEE Transactions on Power Electronics, vol. 34, no. 8, pp. 7521-7531, Aug. 2019.

[25] M. B. Said-Romdhane, et al., "An improved LCL filter design in order to ensure stability without damping and despite large grid impedance variations," Energies, vol. 10, no. 3, 2017.

[26] Global sustainable energy solutions, "Inverter power factor modes: How do they affect voltage rise calculations?" GSES technical papers, 2017. https://www.gses.com.au/wp-content/uploads/2017/05/GSES_powerfactor-2-1.pdf (accessed on December 24, 2019).

[27] S. O. Amrouche, et al., "Reactive power issues in grid connected photovoltaic systems," International Conference on Nuclear and Renewable Energy Resources, 2014, 26-29 October, Antalya, Turkey.

[28] C. Hicks, et al., "Power quality of residential PV system under low solar irradiance and off-grid operation, $18^{\text {th }}$ International Conference on Harmonics and Quality of Power, 2018. ICHQP 2018. Ljubljana, Slovenia, 13-16, 2018. 